\title{
SCIENTIFIC REPRTS OPEN Publisher Correction: Gene-based Therapy in a Mouse Model of Blue Cone Monochromacy
}

\author{
Yuxin Zhang ${ }^{1,2}$, Wen-Tao Deng ${ }^{1}$, Wei Du ${ }^{1,7}$, Ping Zhu ${ }^{1}$, Jie Li ${ }^{1}$, Fan $\mathrm{Xu}^{1,3}$, Jingfen Sun ${ }^{1,8}$, Cecilia \\ D. Gerstner ${ }^{4}$, Wolfgang Baehr ${ }^{4}$, Sanford L. Boye ${ }^{1}$, Chen Zhao ${ }^{2,5}$, William W. Hauswirth ${ }^{1}$ \& \\ Ji-jing Pang ${ }^{1,2,6}$
}

Correction to: Scientific Reports https://doi.org/10.1038/s41598-017-06982-7, published online 27 July 2017

The original version of this Article contained errors in the spelling of the author Sanford L. Boye, which was incorrectly given as L. Boye Sanford. This has now been corrected in both the PDF and HTML versions of the Article.

(c) (i) Open Access This article is licensed under a Creative Commons Attribution 4.0 International Cicense, which permits use, sharing, adaptation, distribution and reproduction in any medium or format, as long as you give appropriate credit to the original author(s) and the source, provide a link to the Creative Commons license, and indicate if changes were made. The images or other third party material in this article are included in the article's Creative Commons license, unless indicated otherwise in a credit line to the material. If material is not included in the article's Creative Commons license and your intended use is not permitted by statutory regulation or exceeds the permitted use, you will need to obtain permission directly from the copyright holder. To view a copy of this license, visit http://creativecommons.org/licenses/by/4.0/.

(c) The Author(s) 2018

\footnotetext{
${ }^{1}$ Ophthalmology, University of Florida, Gainesville, FL, USA. ${ }^{2}$ Department of Ophthalmology, First Affiliated Hospital, Nanjing Medical University, Nanjing, Jiangsu, China. ${ }^{3}$ Department of Ophthalmology, People's Hospital of Guangxi Zhuang Autonomous Region, Nanning, Guangxi, China. ${ }^{4}$ Opthalmology and Visual Sciences, University of Utah, Salt Lake City, UT, USA. ${ }^{5}$ Department of Ophthalmology and Vision Science, Eye \& ENT Hospital, Shanghai Medical College, Fudan University, Shanghai, China. ${ }^{6}$ Xiamen Eye Center of Xiamen University, Xiamen, Fujian, China. ${ }^{7}$ Present address: Ophthalmology Department of Peking University People's Hospital, Peking University People's Eye Center and Eye Institute, Beijing, China. ${ }^{8}$ Present address: Department of Obstetrics and Gynecology, Shanxi Dayi Hospital, Taiyuan, Shanxi Province, China. Yuxin Zhang, Wen-Tao Deng and Wei Du contributed equally to this work. Correspondence and requests for materials should be addressed to C.Z. (email: dr_zhaochen@163. com) orW.W.H. (email: hauswrth@ufl.edu) or J.-j.P. (email: jpang@ufl.edu)
} 